\title{
Twins and maternal smoking: ordeals for the fetal origins hypothesis? A cohort study
}

\author{
Sheila Williams, Richie Poulton
}

\begin{abstract}
Objective To assess the direct and indirect effects of being a twin, maternal smoking, birth weight, and mother's height on blood pressure at ages 9 and 18 years.

Design Longitudinal study.

Subjects Cohort born in 1972-3.

Setting Dunedin, New Zealand.

Main outcome measure Blood pressure at ages 9 and 18 years.

Results Compared with singletons, twins had a systolic blood pressure 4.55 (95\% confidence interval 1.57 to 7.52$) \mathrm{mm} \mathrm{Hg}$ lower at age 9 after adjustment for direct and indirect effects of sex, maternal smoking, mother's height, socioeconomic status, and birth weight, as well as concurrent height and body mass index. Blood pressure in children whose mothers had smoked during pregnancy was 1.54 (0.46 to 2.62$) \mathrm{mm} \mathrm{Hg}$ higher than in those whose mothers did not. The total effect of birth weight on systolic blood pressure at age 9 was $-0.78(-1.76$ to $0.20) \mathrm{mm} \mathrm{Hg}$ and that for mother's height was 0.10 (0.06 to 0.14$) \mathrm{mm} \mathrm{Hg}$. Similar results were obtained for systolic blood pressure at age 18. The total effect of twins, maternal smoking, and birth weight on diastolic blood pressure was not significant at either age.

Conclusions Twins had lower birth weight and lower systolic blood pressure at ages 9 and 18 than singletons. This finding challenges the fetal origins hypothesis. The effect of maternal smoking was consistent with the fetal origin hypothesis in that the infants of smokers were smaller and had higher blood pressure at both ages. This may be explained by pharmacological rather than nutritional effects. The total effect of birth weight on systolic blood pressure, after its indirect effect working through concurrent measures of height and body mass index was taken into account, was small.
\end{abstract}

\section{Introduction}

Studies reporting an inverse association between birth weight and blood pressure in both children and adults have led to the hypothesis that events occurring before birth may lead to cardiovascular disease in later life. ${ }^{12}$ It is argued that this is the consequence of the mother's poor nutrition in pregnancy. Although not all findings confirm this hypothesis, ${ }^{3-5}$ support comes from several studies of people born in the 1920s and 1930s and from children born more recently. The evidence, as a $B M J$ editorial puts it, is an inductionist's dream; example being piled on example, with each study being somewhat consistent with others but none seriously testing the hypothesis. ${ }^{6}$ This editorial suggests ordeals or tests to which the hypothesis might be put, including the effect of being a twin, a group known to experience restricted growth in the third trimester of pregnancy; smoking by the mother, which is a key determinant of birth weight and smoking in the offspring; and social class both at the time of birth and in the mother's family.

This sample from New Zealand provided an opportunity to re-examine the association between birth weight and later blood pressure. Information was available on mothers' height, which can be regarded as a measure of the socioeconomic climate of their childhood as well as the socioeconomic climate prevailing at the time of the children's birth.

\section{Methods}

The sample consisted of children enrolled in the Dunedin multidisciplinary health and development study. This cohort was born at Dunedin's only obstetric hospital between 1 April 1972 and 31 March 1973. Their mothers were resident in the Dunedin metropolitan area at the time of the children's birth.

The sample was traced at the time of the children's third birthdays, and consent was given for 1037 of the 1139 still living in Dunedin or Otago to take part. The sample was seen at intervals of 2 years between ages 3 and 15 and again at ages 18 and $21 .^{7}$ The present study uses data collected at age 9, when 818 children attended the research unit for physical measurements and their mothers were asked about smoking in pregnancy, and at age 18, when 879 attended the unit for a full day's assessment.

In each phase of the study, the same instruments were used for all participants. Blood pressure was measured using a London School of Hygiene blind mercury sphygmomanometer. Systolic blood pressure was taken as the first Korotkoff sound and diastolic as the fourth. Blood pressure was based on the mean of three measures at age 9 and two at age 18 taken in the recumbent position. Stature was measured to the nearest millimetre with a portable Harpenden stadiometer. Weight was recorded to the nearest $0.1 \mathrm{~kg}$ with a Lindell beam balance, the participants being weighed in light clothing. Body mass index was calculated as weight $/$ height ${ }^{2}$ with units $\mathrm{kg} / \mathrm{m}^{2}$. The measurement of blood pressure was one of a number of different assessments undertaken by the participants and was not always completed because of time constraints.

This cohort was part of a larger study in which details of both antenatal and perinatal events were recorded for babies born at Queen Mary Hospital for a period from 1967 to $1973 .{ }^{8}$ Birth weight and mother's height were derived from this. Socioeconomic status for the infants' fathers was recorded, using the Elley-Irving index of socioeconomic status ${ }^{9}$; children whose fathers had occupations in the semiskilled and unskilled categories (5 and 6) were defined as low socioeconomic status, and children of mothers who were unmarried were assigned to another category. Where data were missing for socioeconomic status the

\author{
Editorial \\ by Delamothe et al \\ Department of \\ Preventive and \\ Social Medicine, \\ Dunedin School of \\ Medicine, \\ University of Otago, \\ Box 913, Dunedin, \\ New Zealand \\ Sheila Williams, \\ senior research fellow \\ Dunedin \\ Multidisciplinary \\ Health and \\ Development \\ Research Unit, \\ Department of \\ Preventive and \\ Social Medicine \\ Richie Poulton \\ senior research fellow \\ Correspondence to: \\ Ms Williams \\ sheila.williams@ \\ stonebow.otago.ac.nz
}


Table 1 Characteristics of males and females at age 9 and 18 years. Values are means (SD)

\begin{tabular}{lcr} 
Characteristic & Males & Females \\
\hline Age 9: & $(\mathrm{n}=419)$ & $(\mathrm{n}=376)$ \\
\hline Systolic blood pressure $(\mathrm{mm} \mathrm{Hg})^{*}$ & $107.0(7.28)$ & $106.1(7.24)$ \\
\hline Diastolic blood pressure $(\mathrm{mm} \mathrm{Hg}) \dagger$ & $68.7(6.71)$ & $68.5(7.03)$ \\
\hline Body mass index $\left(\mathrm{kg} / \mathrm{m}^{2}\right)$ & $16.3(1.55)$ & $16.4(1.77)$ \\
\hline Height $(\mathrm{cm})$ & $132.7(5.41)$ & $131.8(5.77)$ \\
\hline Birth weight $(\mathrm{kg})$ & $3.4(0.53)$ & $3.3(0.52)$ \\
\hline Mother's height $(\mathrm{cm})$ & $162.7(5.68)$ & $163.1(6.01)$ \\
\hline Age 18: & $(\mathrm{n}=444)$ & $115.4(9.27)$ \\
\hline Systolic blood pressure $(\mathrm{mm} \mathrm{Hg})$ & $126.0(9.38)$ & $56.8(9.06)$ \\
\hline Diastolic blood pressure $(\mathrm{mm} \mathrm{Hg}) \ddagger$ & $56.8(10.57)$ & $22.9(3.17)$ \\
\hline Body mass index $\left(\mathrm{kg} / \mathrm{m}^{2}\right)$ & $22.7(3.17)$ & $164.1(6.08)$ \\
\hline Height $(\mathrm{cm})$ & $176.1(6.21)$ & $3.3(0.51)$ \\
\hline Birth weight $(\mathrm{kg})$ & $3.5(0.53)$ & $163.2(6.13)$ \\
\hline Mother's height $(\mathrm{cm})$ & $162.7(5.81)$ &
\end{tabular}

${ }^{*}$ Recorded for 811 children, but analysis restricted to children with no data missing.

†1 Observation missing in each group.

$\ddagger 13$ Observations missing for males and 4 observations missing for females.
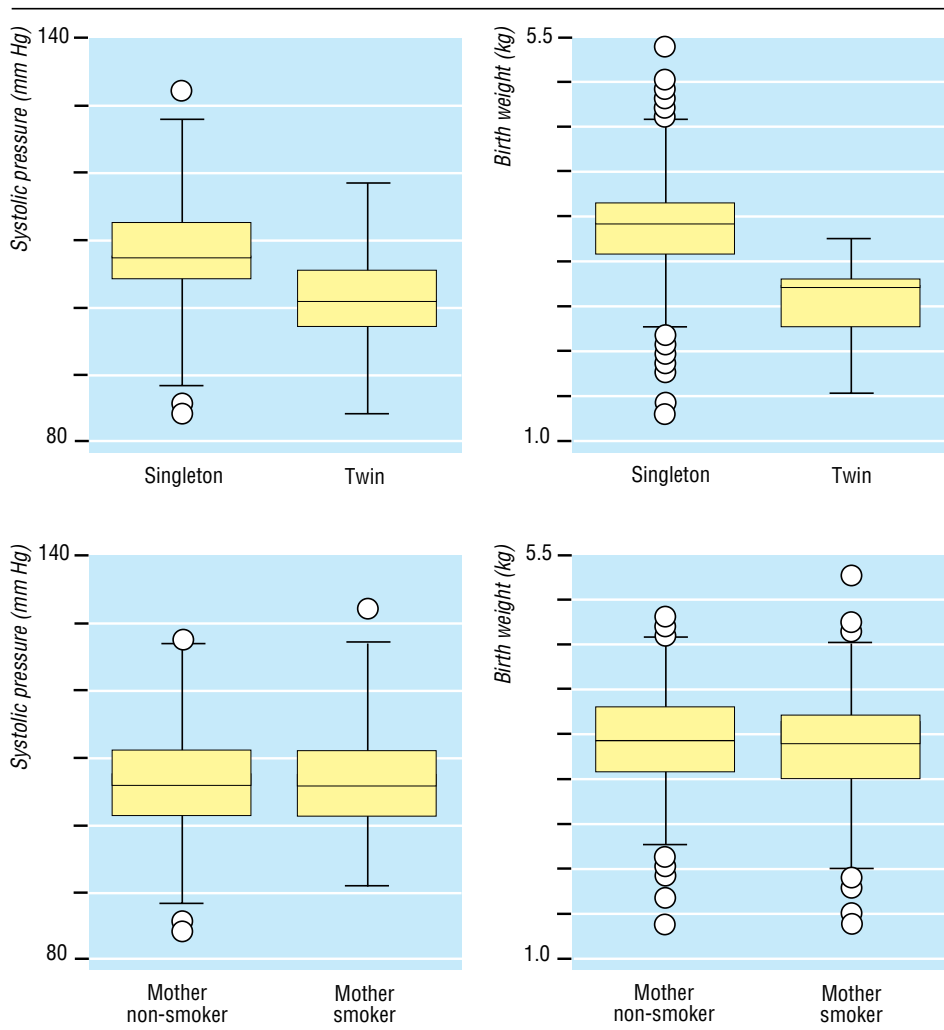

Fig 1 Box and whisker plots for systolic blood pressure at age 9 and birth weight for twins compared with singletons, and children of mothers who smoked during pregnancy compared with children of mothers who did not smoke

mother's socioeconomic status recorded at the birth or socioeconomic status collected at age 3 was substituted.

As part of the assessment at age 9 the mothers of the children were asked whether or not they had smoked in pregnancy and were classified as smokers or non-smokers. Mother's height was recorded at assessment at age 11, and this was used if mother's height had not been recorded at the time of the child's birth.

Path analysis was used to examine the effect of maternal smoking, mother's height, and being a twin on birth weight as well as their effect on later height, body mass index, and blood pressure. The models were fitted with LISREL using maximum likelihood methods. ${ }^{10}$ In the analysis, the temporal nature of the variables was used to examine the causal relations among them. As the mother's height was established and maternal smoking occurred before the baby was born, these variables were regarded as being causally related to birth weight. Birth weight was considered to be causally related to measures taken at ages 9 and 18 years. Although height, body mass index, and blood pressure were collected simultaneously, a causal relation between both body mass index and height and blood pressure was tenable. This mediates the direct and indirect effects of birth weight and other variables on blood pressure.

\section{Results}

Systolic blood pressure was recorded for 811 children at age 9 but the analysis was restricted to 419 boys and 376 girls because data for some of the other variables were missing (see below). The means and standard deviations for systolic blood pressure, height, body mass index, birth weight, and mother's height are shown in table 1 . The sample included $22(2.8 \%)$ twins and $261(32.8 \%)$ children whose mothers reported smoking in pregnancy. Information on whether or not the mothers smoked was not available for $40(5.0 \%)$ children. The sample also included 177 (22.3\%) children in the low socioeconomic status category and $36(4.5 \%)$ whose mothers were unmarried at the time of their conception. Height and weight at age 9 were missing for five children, mother's height for two, and socioeconomic status for nine. The mean birth weight for the 242 children not included in this study was 3.35 (SD 0.50) kg compared with $3.38(0.53) \mathrm{kg}$ for those included. The mean of the mothers' heights was 163.0 (6.58) $\mathrm{cm}$ for children who were excluded and 162.9 (5.84) $\mathrm{cm}$ for those included. Of those excluded 125 $(51.7 \%)$ were boys, $4(1.6 \%)$ were twins, $53(21.9 \%)$ were categorised as of low socioeconomic status, and 6 $(2.5 \%)$ had single mothers.

Box and whisker plots for systolic blood pressure and birth weight for single and twin births, and for children whose mothers were and were not smokers, are shown in figure 1 . These indicate that on average twins had both lower blood pressure at age 9 and lower birth weights than singleton children (difference 5.09 (95\% confidence interval 2.03 to 8.16$) \mathrm{mm} \mathrm{Hg}$ for blood pressure and 0.88 (0.66 to 1.09$) \mathrm{kg}$ for birth weight). The children of mothers who smoked in pregnancy had higher blood pressure (difference 1.41 (0.32 to 2.50$) \mathrm{mm} \mathrm{Hg}$ ) and lower birth weights (difference $0.11(0.03$ to 0.19$) \mathrm{kg})$ than those whose mothers did not smoke.

Regressing systolic blood pressure on birth weight in the total population of births showed an inverse relation: a difference of $1 \mathrm{~kg}$ in birth weight was commensurate with a decrease in blood pressure of 0.26 (0.70 to 1.21$) \mathrm{mm} \mathrm{Hg}$. Mother's height was positively related, with a difference of $1 \mathrm{~cm}$ being commensurate with a difference of 0.07 ( -0.02 to 0.15$)$ $\mathrm{mm} \mathrm{Hg}$. The results of regressing systolic blood pressure at age 9 on all the variables simultaneously is shown in table 2. These are the direct effects of each variable on blood pressure. Being a twin, maternal smoking, the concurrent measures of body mass index 
Table 2 Regression coefficients for effects of predictors of systolic blood pressure at age 9 adjusted for other variables in model

\begin{tabular}{lccc} 
& Direct effect $(95 \%$ Cl) & Indirect effect (95\% Cl) & Total effect (95\% CI) \\
\hline Sex & $0.76(-0.20$ to 1.72$)$ & $-0.02(-0.39$ to 0.35$)$ & $0.74(-0.27$ to 1.75$)$ \\
\hline Twin & $-4.31(-7.32$ to -1.30$)$ & $-0.80(-2.13$ to 0.54$)$ & $-5.11(-8.18$ to -2.03$)$ \\
\hline Maternal smoking in pregnancy & $1.34(0.31$ to 2.38$)$ & $0.20(-0.19$ to 0.59$)$ & $1.54(0.45$ to 2.63$)$ \\
\hline Maternal smoking status (unknown) & $1.77(-0.54$ to 4.08$)$ & $-0.40(-1.25$ to 0.46$)$ & $1.37(-1.08$ to 3.81$)$ \\
\hline Low socioeconomic status & $-0.34(-1.48$ to 0.81$)$ & $-0.02(-0.44$ to 0.41$)$ & $-0.35(-1.57$ to 0.87$)$ \\
\hline Mother unmarried & $-1.42(-3.83$ to 0.98$)$ & $1.24(0.34$ to 2.15$)$ & $-0.18(-2.72$ to 2.36$)$ \\
\hline Mother's height $(\mathrm{cm})$ & $-0.02(-0.11$ to 0.07$)$ & $0.09(0.05$ to 0.14$)$ & $0.07(-0.02$ to 0.16$)$ \\
\hline Current height $(\mathrm{cm})$ & $0.33(0.23$ to 0.43$)$ & - & $0.33(0.23$ to 0.43$)$ \\
\hline Current body mass index $\left(\mathrm{kg} / \mathrm{m}^{2}\right)$ & $0.92(0.63$ to 1.21$)$ & - & $0.92(0.63$ to 1.21$)$ \\
\hline Birth weight $(\mathrm{kg})$ & $-1.93(-2.89$ to -0.96$)$ & $1.06(0.67$ to 1.46$)$ & $-0.87(-1.86$ to 0.13$)$ \\
\hline
\end{tabular}

and height, as well as birth weight, were all significantly associated with blood pressure. Birth weight was inversely associated with blood pressure, commensurate with a decrease of $1.93(0.96,2.89) \mathrm{mm} \mathrm{Hg}$ for each $\mathrm{kg}$ increase in birth weight. This analysis, however, does not take into account the indirect effects of a number of these variables on blood pressure.

Path analysis was used to estimate both the indirect and the total effects of the measures related to birth weight as well as birth weight itself on the height, body mass index, and blood pressure at age 9 (table 2). As the path model estimated a large number of effects, in the interests of parsimony the direct effects which were not statistically significant were removed. The final model provided a good fit for the data $\left(\chi^{2}=14.07\right.$, $\mathrm{df}=11, \mathrm{P}=0.23)$ The key features of the model are illustrated in figure 2, which shows the standardised regression coefficients. Being male, being a twin, and mother's height were strong predictors of birth weight and later height. Maternal smoking was related to birth weight and later body mass index. In this model the total effect of birth weight on systolic blood pressure included the direct effect, -0.134 ; the indirect effect acting through height, $0.163 \times 0.247$; and the indirect effect acting through body mass index, $0.179 \times 0.207$; leading to total of -0.057 . Thus an increase of one standard deviation in birth weight was associated with a reduction of 0.057 of a standard deviation of systolic blood pressure, which is equivalent to a $1 \mathrm{~kg}$ increase in birth weight, being commensurate with a decrease of 0.78 ( -0.20 to 1.76$) \mathrm{mm} \mathrm{Hg}$ in blood pressure. The direct effect, and indirect effects operating through birth weight and height, produce a total effect for being a twin of $-4.55(-7.52$ to -1.57$) \mathrm{mm} \mathrm{Hg}$. The total effect for maternal smoking was 1.54 (0.46 to 2.62) mm $\mathrm{Hg}$, and that for mother's height $0.10(0.06$ to 0.14$) \mathrm{mm}$ $\mathrm{Hg}$. The correlation between height and body mass index at age 9 was 0.14 . The total effects for the full model are shown in table 2.

We then restricted the analysis for systolic blood pressure at age 9 to the 755 children whose gestational age was believed to be 37 weeks or more. This group included 94 children of unknown gestational age whose mean birth weight was $3.4(0.46) \mathrm{kg}$. Nine children whose gestational age was unknown and who were of low birth weight were excluded. The findings were essentially the same as for the entire sample. The total effect on blood pressure was $-0.49(-1.62$ to $0.64) \mathrm{mm} \mathrm{Hg}$ for birth weight, -4.26 ( -7.75 to -0.77 ) $\mathrm{mm} \mathrm{Hg}$ for being a twin, $1.61(0.50$ to 2.73$) \mathrm{mm} \mathrm{Hg}$ for maternal smoking, and 0.11 (0.07 to 0.14$) \mathrm{mm} \mathrm{Hg}$ for mother's height (table 3).
When the model presented in figure 2 was fitted to the data for diastolic blood pressure at age 9 (table 1) the total effect of birth weight on blood pressure was $-0.10(-1.04$ to 0.84$) \mathrm{mm} \mathrm{Hg}$, that for being a twin was $-1.74(-4.57$ to 1.08$) \mathrm{mm} \mathrm{Hg}$, that for maternal smoking was $0.54(-0.49$ to 1.57$) \mathrm{mm} \mathrm{Hg}$, and the effect for the mother's height was $0.03(-0.01$ to 0.05$)$ $\mathrm{mm} \mathrm{Hg}$.

The analysis was repeated using blood pressure measures obtained at age 18. Systolic blood pressure was available for 851 people at this age. Means and standard deviations for blood pressure and the other variables included in the analysis are shown in table 1 . Observations were available for $21(2.5 \%)$ twins, 237 $(27.8 \%)$ participants whose mothers smoked, and 189 $(22.2 \%)$ whose families were of low socioeconomic status. The model shown in figure 2 was modified by including a direct path from sex to systolic blood pressure, and the path from maternal smoking to current body mass index was excluded because these results were not significant. The total effects on blood pressure were similar to those observed at age 9 . They were -1.17 ( -2.41 to 0.06$) \mathrm{mm} \mathrm{Hg}$ for birth weight, $-4.18(-8.12$ to -0.24$) \mathrm{mm} \mathrm{Hg}$ for twins, $1.95(0.54$ to 3.36$) \mathrm{mm} \mathrm{Hg}$ for maternal smoking, and 0.11 (0.06 to 0.16$) \mathrm{mm} \mathrm{Hg}$ for mother's height.

Fitting the model for diastolic blood pressure at age 18 led to the following estimates: birth weight 1.03 (0.31 to 2.38) $\mathrm{mm} \mathrm{Hg}$, twins 1.19 (-3.10 to 5.49),

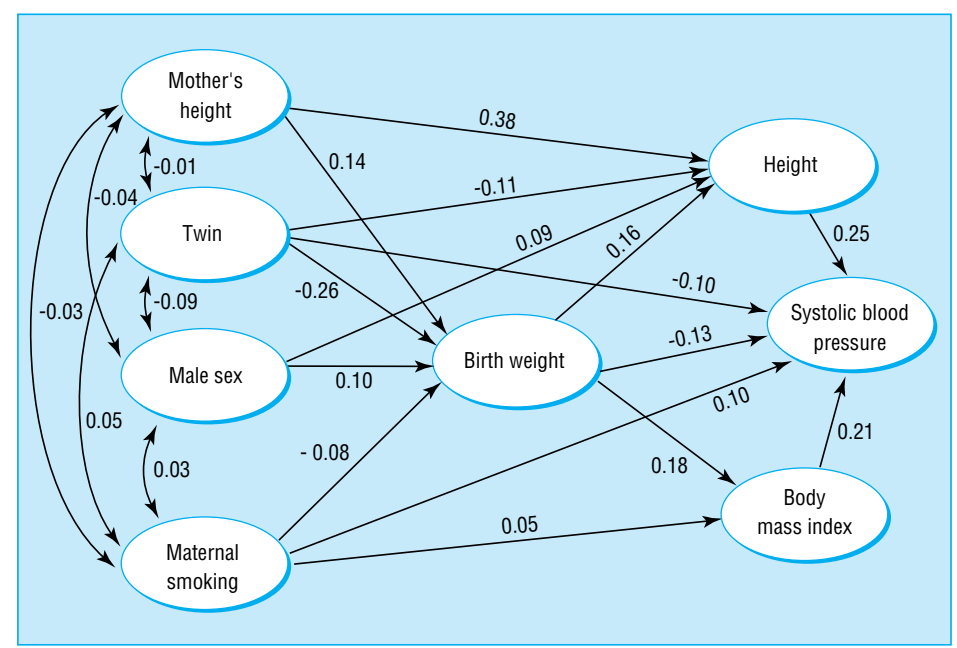

Fig 2 Path diagram for effects of sex, being a twin, mother's smoking, and mother's height on birth weight, and their effects on height, body mass index, and systolic blood pressure at age 9 years 
Table 3 Total effects of birth weight, being a twin, maternal smoking, and mother's height on systolic and diastolic blood pressure at age 9 and 18

\begin{tabular}{lllll} 
& Birth weight & Twin & Mother's smoking & Mother's height \\
\hline Blood pressure at age 9 & & & & \\
\hline Systolic $(n=755)^{*}$ & $-0.49(-1.62$ to 0.64$)$ & $-4.26(-7.75$ to -0.77$)$ & $1.61(0.50$ to 2.73$)$ & $0.11(0.07$ to 0.14$)$ \\
\hline Diastolic $(n=795)$ & $-0.10(-1.04$ to 0.84$)$ & $-1.74(-4.57$ to 1.08$)$ & $0.54(-0.49$ to 1.57$)$ & $0.03(-0.01$ to 0.05$)$ \\
\hline Blood pressure at age $\mathbf{1 8}$ & & & & \\
\hline Systolic $(n=851)$ & $-1.17(-2.41$ to 0.06$)$ & $-4.18(-8.12$ to -0.24$)$ & 1.95 (0.54 to 3.36$)$ & $0.11(0.06$ to 0.16$)$ \\
\hline Diastolic $(n=851)$ & $1.03(0.31$ to 2.38$)$ & $1.19(-3.10$ to 5.49$)$ & $1.15(-0.42$ to 2.72$)$ & 0.05 (0 to 0.11$)$ \\
\hline
\end{tabular}

*Gestational age 37 weeks or more.

maternal smoking 1.15 ( -0.42 to 2.72$)$, and maternal height 0.05 (0 to 0.11$)$.

\section{Discussion}

The significant inverse association between birth weight and systolic blood pressure after adjustment for current height and body mass index at ages 9 and 18 is consistent with the results of a number of studies in both adults and children, several of which are summarised by Barker. ${ }^{2}$ Our results are not altogether consistent with a more recent study of 8-11 year old children, which found that this association held for girls but not boys, ${ }^{11}$ nor with a study of 18 year olds in Israel, which found a weak association. ${ }^{3}$ It has been argued that body mass index is an intervening variable in the relation between birth weight and blood pressure and that to adjust for it in a regression model is to overcontrol for it. ${ }^{6}$ Thus, and because birth weight was not by itself significantly associated with blood pressure in this sample, its importance in the model may be by virtue of its association with other variables.

\section{Statistical considerations}

The direct effects in the path analysis were the same as those obtained from multiple regression, so that the measurement for birth weight provided an estimate of its effect on blood pressure after the effects of other variables were taken into account. Adjusting for confounding in this way assumes that none of the variables included in the model are at an intermediate step in the causal pathway. Path analysis, unlike multiple regression analysis, allows for the inclusion in the model of variables such as current height and body mass index which are in the causal pathway. Hence the total effect of birth weight on blood pressure can be estimated from the direct and the indirect effects. The results of this study showed that birth weight was strongly associated with later height and body mass index, which were in turn strongly associated with blood pressure. This resulted in a significant positive indirect effect and, combined with the inverse direct effect, provided an estimate of the total effect.

\section{Ordeals for the fetal origins hypothesis}

The most interesting finding of this study was the lower systolic blood pressure of twins. The magnitude of this effect was similar whether or not adjustments were made for birth weight or concurrent height or body mass index. Further, this finding was significant when the analysis was restricted to full term infants at age 9 and when the whole sample was examined at age 18 . This finding is not consistent with the fetal origins hypothesis, which argues that poor nutrition in pregnancy leads to higher rather than lower blood pressure. A recent Danish study showed that twins do not have significantly different mortality from cardiovascular disease than the general population, even though they experience intrauterine growth delay. ${ }^{12}$ The authors concluded that the fetal origins hypothesis did not apply to the growth retardation experienced by twins. Other studies have found that variables plausibly reflecting poor maternal nutrition, including low maternal body mass index before pregnancy, poor maternal weight gain in pregnancy, and being born small for gestational age, were not associated with higher blood pressure. ${ }^{13}$

The path analysis showed that mother's height had a positive effect on blood pressure, acting indirectly through children's height. Studies that have shown the reverse have not taken into account the indirect effect of maternal height. A study of the British 1946 birth cohort, for example, showed that the 36 year old sons of the tallest mothers had blood pressures $2 \mathrm{~mm} \mathrm{Hg}$ lower than the sons of the shortest mothers, and this increased to almost $3 \mathrm{~mm} \mathrm{Hg}$ when adjusted for current weight. ${ }^{14}$ The differences were not as clear cut among the women. This effect was also evident among children born in Salisbury in 1984-5..$^{15}$ The authors of these reports argue that a woman's physique depends on her nutrition in childhood, and that this may be linked to blood pressure in the next generation. In our sample a difference in height of $10 \mathrm{~cm}$ was commensurate with a $1 \mathrm{~mm} \mathrm{Hg}$ difference in blood pressure.

The model in figure 2 showed that maternal smoking worked in three plausible ways. In some senses this finding is consistent with the fetal origins hypothesis in that maternal smoking was associated with both lower birth weight and higher blood pressure if it is assumed that maternal smoking leads to poorer nutrition for the fetus. As smoking also predicts body mass index at age 9 it seems possible that this is an effect of social environment because it is well known that maternal smoking is associated with low socioeconomic status and lower school achievement and may be a proxy for a poorer home environment or poorer nutrition. ${ }^{16}$ Indeed, a study of the mothers of these children carried out in 1994 found that those who smoked met fewer of the New Zealand nutritional guidelines. ${ }^{17}$ It also seems possible that smoking has non-nutritional effects that exert a direct effect on the fetus and that this may be mediated by an effect on the placental circulation. ${ }^{16}$ Another study has examined the association between maternal smoking and blood pressure and shown non-significant differences of about $1 \mathrm{~mm} \mathrm{Hg}$ in blood pressure between the 4 year old children of mothers who smoked 20 or more cigarettes a day and those of mothers who did not smoke in pregnancy. ${ }^{15}$ 
The authors concluded that although smoking was associated with reduced placental weight it was not related to children's blood pressure. The result in this report could be affected by recall bias because information about smoking in pregnancy was collected after a nine year interval; however, its effects on birth weight are consistent with what is known and it is likely that women remember whether or not they smoked in pregnancy. Studies have shown that people may have difficulty recalling how much they smoked rather than whether or not they smoked. ${ }^{18}$ The finding that the path between maternal smoking and body mass index at age 18 was not significant may mean that the family social environment was less influential at that age.

\section{Conclusions}

The fetal origins hypothesis has been subjected to as tough an ordeal as the data permit. The crucial tests were the effects of being a twin and maternal smoking on the relation with systolic blood pressure. That twins had lower blood pressure at age 9 and 18 challenges the underlying premise of the fetal origin hypothesis. On the other hand, smoking affects both birth weight and blood pressure itself and the associations were consistent with the fetal origins hypothesis provided that its action is explained by poor nutrition. Taken in total, mother's height had a positive effect on blood pressure, suggesting that taller women had larger babies, taller children, and children with higher blood pressure. When the indirect effect of birth weight on current height and body mass index was taken into account, it seems that the direct effect of birth weight on later blood pressure may be overestimated.

We thank Professor Jim Mann, with whom this paper was discussed, and acknowledge the support of Dr Phil Silva, of those who collected the data, and of the participants who have so willingly taken part in this longitudinal study.

Contributors: SW conceived the idea for this study and carried out the statistical analysis for this study. The paper was written jointly by SW (guarantor) and RP.

Funding: The Dunedin Multidisciplinary Health and Development Research Unit and the authors are supported by the Health Research Council of New Zealand. The New Zealand National Heart Foundation provided support for the blood pressure studies

Competing interests: None declared.
Key message

- Twins have lower systolic blood pressure at age 9 and 18 years than singletons

- Children of mothers who smoke in pregnancy have a lower mean birth weight and a higher mean systolic blood pressure at age 9 and 18 .

- When the indirect effects of birth weight on current height and body mass index are taken into account the effect of birth weight on blood pressure is small at ages 9 and 18

1 Barker DJP. Fetal and infant origins of adult disease. London: BMJ, 1992

2 Barker DJP. Mothers, babies, and disease in later life. London: BMJ, 1994.

3 Seidman DS, Laor A, Gale R, Stevenson DK, Mashiach S, Danon YL Birth weight, current body weight, and blood pressure in late adolescence. BMJ 1991;302:1235-7.

4 Williams SM, St George IM, Silva PA. Intrauterine growth retardation and blood pressure at age seven and eighteen. J Clin Epidemiol 1992;45:125763

5 Matthes JWA, Lewis PA, Davies DP, Bethel JA. Relation between birth weight at term and systolic blood pressure in adolescence. $B M$ J 1994;308:1074-7

6 Paneth N, Susser M. Early origins of coronary heart disease (the "Barker hypothesis"). BMJ 1995;310:411-2.

7 Silva PA, Stanton WR, eds. From child to adult. The Dunedin multidisciplinary health and development study. Auckland: Oxford University Press, 1996.

8 Buckfield PM. Perinatal events in the Dunedin City population 1967-1973. NZ Med J 1978;88:244-6.

9 Elley WB, Irving JC. A socioeconomic index for New Zealand based on levels of education and income from 1966 census. NZ J Educ Stud 1972;7:153-67.

10 Jöreskog KG, Sorböm D. LISREL 8 user's reference guide. Chicago: Scientific Software International, 1993.

11 Taylor SJC, Whincup PH, Cook DG, Papacosta O, Walker M. Size at birth and blood pressure: cross sectional study in 8-11 year old children. $B M J$ 1997;314:475-80.

12 Christensen K, Vaupel JW, Holm NV, Yashin AI. Mortality among twins after age 6: fetal origins hypothesis versus twin method. $B M J$ 1995;310:432-6.

13 Laor A, Stevenson DK, Shemer J, Gale R, Seidman DS. Size at birth, maternal nutritional status in pregnancy, and blood pressure at age 17 : population based analysis. BMJ 1997;315:449-53.

14 Barker DJP, Osmond C, Golding J, Kuh D, Wadsworth MEJ. Growth in utero, blood pressure in childhood and adult life, and mortality from cardiovascular disease. BMJ 1989;298:564-7.

15 Law CM, Barker DJP, Bull AR, Osmond C. Maternal and fetal influences on blood pressure. Arch Dis Child 1991;66:1291-5.

16 Logan S, Spencer N. Smoking and other health related behaviour in the social and environmental context. Arch Dis Child 1996;74:176-9.

17 Olaman SJ. The Dunedin women's health study: a quantitative and qualitative study of the health and well being of a sample of New Zealand women in midlife [dissertation]. Dunedin: University of Otago, 1997.

18 Gunner P-G, Norrell SE. Retrospective versus original information on cigarette smoking. Am J Epidemiol 1989;130:705-11.

(Accepted 9 November 1998)

Cite this article as:

Williams S, Poulton R. Twins and maternal smoking: ordeals for the fetal origins hypothesis [abridged version]. BMJ 1999;318:897-900. (full version: www.bmj.com/cgi/content/full/318/ $7188 / 897)$ 